\title{
Bed Expansion Characteristics of \\ Liquid-Solid Fluidized Bed with Internals
}

\author{
E. Ramaswamy \\ Department of Chemical Engineering \\ Coimbatore Institute of Technology \\ Coimbatoe-641014 \\ India \\ C.Srinivasakannan \\ Monash University Malaysia \\ 2-Jalan University \\ Bandar Sunway \\ 46150 Petaling Jaya \\ Selangor \\ Malaysia \\ N.Balasubramaniam (Corresponding author) \\ Department of Chemical Engineering \\ A.C.Tech. Campus \\ Anna University-Chennai \\ Chennai-600 025 \\ India \\ Tel: 91-44-22203501Ｅ-mail: nbsbala@annauniv.edu
}

\begin{abstract}
It is attempted in the present investigation to study the influence of internals in the riser of liquid-solid fluidized bed. Experiments on bed expansion characteristics in liquid-solid fluidized bed have been carried out in a conventional liquid-solid fluidized bed and in a fluidized bed having string plates of spheres and twisted tapes as internals covering wide range in operating conditions. It has been observed in the present investigation that an increase in particle diameter, density and twist ratio is found to decrease the bed voidage and an increase in the pitch of the string increases the bed voidage. Further it has been observed that the bed voidage is higher in fluidized bed without internals when compared to fluidized bed with internals for a given operating conditions. A model based on slip velocity has been developed for predicting bed voidage and observed that more than $92 \%$ of the experimental data match with the model predictions within $10 \%$ error.
\end{abstract}

Keywords: Liquid-solid fluidized bed, Internals, Bed expansion, Slip velocity

\section{Introduction}

Fluidized beds find extensive applications in chemical process industries as they provide large interfacial area, high degree of mixing, and temperature uniformity. In particular, liquid-solid fluidized beds are increasingly used in chemical processes such as fermentation, biological wastewater treatment, flue gas desulfurization, ore reduction etc. Although fluidization can be achieved either by liquid or gas as fluidizing medium, gas fluidized beds have gained more importance in scientific community due to its far more applications. This is in spite of the fact that possible uses of liquid fluidisation in the mining industry were suggested as early as in 16th century as a means of separating solids of different sizes. Since the emergence of biosciences in the recent years and the adaptability of liquid fluidized bed for various applications, the importance of solid-liquid fluidized bed is receiving greater attention among scientists and researches (Yang \& Renken, 1998, pp. 537-544). 
In recent years, the applications of liquid-solid fluidized beds are being extended for hydrometallurgy, food technology, biochemical processing, water treatment, etc (Narvaez, Orio, Aznar \& Corella, 1996, pp. 2110-2120. Olivares, Aznar, Caballero, Gil, Frances \& Corella, 1997, pp. 5220- 5226. Narvaez, Orio, Aznar \& Corella, 1996, pp.2110-2120). Scientific research concerns with reference to the hydrodynamic structure of liquid-particles, the equilibrium forces for fluid-particle interactions and heat or mass transfer properties in fluidized beds. Fluidization quality is closely related to the intrinsic properties of particles, e.g. particle density, particle size and size distribution, and also their surface characteristics. The expansion characteristic of solid particles in a liquid-solid fluidized bed is a function of superficial liquid velocity. A quantitative relationship linking the bed expansion with these parameters is necessary for a fundamental understanding of fluidization behavior and subsequent applications (Richardson \& Jeronimo, 1979, pp. 1419-1422. Kmiec, 1982, pp.133-136).

The bed expansion characteristic is an important parameter in the design of fluidized beds. Extensive work has been reported on bed expansion characteristics in liquid-solid fluidized bed. A comprehensive work attempted by Renzo Di Felice (Renzo, 1995, pp. 1220-1225) identified four different types of bed expansion behavior with gradual transition from one to another occurring as the physical conditions are changed. Suitable predictive bed expansion equations for each of the region were presented. Although the use of internals to reduce axial mixing and enhance the conversion in liquid phase is well known, studies relating to bed expansion characteristics in liquid-solid fluidized bed with internals are very scarce. It is attempted to study bed expansion characteristics of liquid-solid fluidized beds with internals such as twisted tapes and string of spheres in the present study. A theoretical work is attempted to predict the bed expansion characteristics, based on slip velocity.

\section{Experimental}

The schematic representation of experimental set-up shown in Figure 1, consist of a glass column of $75 \mathrm{~mm}$ internal diameter and height of $750 \mathrm{~mm}$. The column has three sections: calming section (7) at the bottom, test section (8) in the middle and disengaging section (9) at the top of the column. Glass beads and sand particles of different sizes were used as solids particles. The fluidizing particles are supported by a wire mesh having $1.5 \mathrm{~mm}$ perforation fitted at the bottom column. PVC solids spears of $25 \mathrm{~mm}$ and $50 \mathrm{~mm}$ diameters were fixed on a $3 \mathrm{~mm}$ rod were used as internals. The spheres pitch has been varied from one column diameter to 3-column diameter to check the effect of the pitch on bed hydrodynamics. Similarly the diameter of twisted tapes were $25 \mathrm{~mm}$, and the twist ratio varied from 3.22 to 14.44 . The liquid from the storage tank was pumped through a control valve (4) and the flow rate was measured by a rotameter (3) connected on the line. The liquid enters the through calming section (7) and leaves through disengaging section (9). The disengaging section has the provision for addition of particles into the test section. The column pressure drop has been estimated using a $U$ tube manometer connected via pressure tappings (6). The height of solids in the column was measured with respect to change in flow rate of the liquid and bed voidage. The bed voidage can be estimated using the fluidization equation,

$\Delta P=\frac{W}{A}=L(1-\varepsilon)\left(\rho_{S}-\rho_{l}\right)$

Experiments were carried out covering a wide range in operating conditions and the results are presented in the Figures 2-7. The minimum fluidization velocity for the solids materials has been estimated using Wen and $\mathrm{Yu}$ (Wen and $\mathrm{Yu}$, 1962, pp.100) equation, i.e.

$$
U_{m f}=\frac{\mu_{g}}{d_{p} \rho_{g}} \sqrt{(33.7)^{2}+0.0408 \frac{d_{p}{ }^{3} \rho_{g}\left(\rho_{s}-\rho_{g}\right) g}{\mu_{g}{ }^{2}}}-33.7
$$

The minimum fluidization velocity has also been estimated experimentally. It has been observed that the experimental prediction match with the prediction using equation (2) within $\pm 5 \%$ error. The Figure 2 shows the variation of bed voidage with liquid velocity. It can be seen from figure 2 that the bed voidage increases with an increase in liquid velocity. The rate of increase of bed voidage is high at the beginning and gradually reduced to marginal with liquid rate. It can also be ascertained from the figure that the voidage decreases with increasing solid particle size. These observations are in qualitative agreement with the observations reported in literature (Handley, Doraisamy, Butcher and Franklin, 1966, pp. 260-273). Similar observation has been recorded for the system having twisted taps as internals [Figure 3].

Experiments were carried out with sand and glass beads of same size, to study the effect of particle density on bed voidage and the observations are given is given in Figure 4. It can be ascertained from Figure 4 that an increase in the particle density decreases the bed voidage. An increase in bed voidage with decrease in particle size and density is well understood in conventional fluidization and the present observations are in qualitative agreement the reported literature. 
An increase in particle density leads to an increase in the particle Archimedes number, i.e. the gravitational forces resulting in reduction in bed voidage.

The Figures $5 \& 6$ show the effect of pitch of sphere pitch and twist ratio on bed voidage. It can be ascertained from the figures that the bed voidage increases with an increase in the pitch of the spheres as well as the twist ratios of twisted tapes. An increase in twist ratio reduces the number of twists in the bed while with an increase in the pitch of

the spheres reduces the number of spheres in the bed resulting in an increase in the bed voidage. This can be explained that the presence of internals reduces the bed voidage due to i) hindrance effect on free upward flow of fluidizing particle ii) formation of eddies. The liquid move along the internals resulting in the localization of solids in eddies. This is evident from the higher bed voidage in fluidized bed without internals as compared to fluidized bed with internals under similar fluidization conditions.

\section{Slip Velocity}

Solids concentration in a liquid-solid fluidized bed may be considered to depend upon the relative velocity particle characteristics (Richardsonand Zaki, 1954, pp. 35-53) i.e.

$\varepsilon=\mathrm{f}\left(\mathrm{U}_{\mathrm{s}}, \mathrm{d}_{\mathrm{p}}, \rho_{\mathrm{s}}\right)$

where Us is the slip velocity between the phases, which is defined as the relative velocity difference between the phases, i.e.

$U_{s}=\frac{\mathrm{U}_{\mathrm{c}}}{\varepsilon} \pm \frac{U_{d}}{1-\varepsilon}$

where $U_{c}$ and $U_{d}$ refer the true velocity of continuous and dispersed phases respectively. when $U_{c}$ is zero $U_{d}$ tends to zero. The positive sign refers to counter current operation while negative sign represents concurrent operation. Slip velocity defined as above represents free fall velocity of a single particle in an infinite medium. However in a medium of finite particle population, it differs from the free fall velocity due to the presence of other particles. Several empirical models and correlations have been proposed to predict the relative velocity between the phases. Barnea $\&$ Mizrahi (Barnea \& Mizrahi., 1973, pp. 171) considered in detail for creeping flow, the hindrance effects in sedimentation and fluidization and classified them into, pseudo hydrostatic effect, momentum transfer effect and wall hindrance effect. Taking into account all these effects the authors proposed the following equation for fluidization of liquid drops,

$$
\frac{U_{s}}{U_{t}}=\frac{\varepsilon}{\left(\left[1+(1-\varepsilon)^{\frac{1}{3}}\right] \exp \frac{5(1-\varepsilon)}{3 \varepsilon}\right)}
$$

$\mathrm{U}_{\mathrm{s}} / \mathrm{U}_{\mathrm{t}}$ is the ratio of true fall velocity of a particle in medium of particle population, to the free fall velocity of a particle in an infinite medium. ' $\varepsilon$ ' in the numerator arises from choosing the mixture density for buoyancy effect, the pre-exponential term in denominator accounts for hindrance effect due to the presence of other particles, the exponential term is the correction due to the momentum transfer effect. Since the momentum transfer and hindrance effects are introduced in terms of particle holdup, the above equation may be modified and written as,

$\frac{U_{s}}{U_{t}}=\frac{\varepsilon^{n}}{\left(1+(1-\varepsilon)^{1 / 3}\right)^{m}}$

$\mathrm{n}$ is equal to 1 for creeping flow and $2 / 3$ for intermediate flow range of Reynolds number. The experimental data of the present study corresponds to the intermediate range of Reynolds number $\left(1<\mathrm{Re}_{\mathrm{t}}<1000\right)$. Substituting the single particle rise velocities in infinite medium for intermediate region the corresponding equation for slip velocity is,

$U_{s}=\left[\frac{4 g d_{p} \Delta \rho}{3 k \rho_{l}^{0.5} \mu^{0.5}}\right]^{2 / 3}\left[\frac{\varepsilon^{2 / 3}}{\left(1+(1-\varepsilon)^{1 / 3}\right)^{2 m / 3}}\right]$

Where $\mathrm{k}=10$ for specified Reynolds number range.

The index $\mathrm{m}$ accounts for particle-particle, particle-wall effects. The value of $\mathrm{m}$ is has been evaluated using experimental data for the specified Reynolds number range covered in the present investigation by minimizing the error as given in following equation:

$$
\sqrt{\frac{\sum\left(U_{S_{\text {exp }}}-U_{S_{\text {pred }}}\right)^{2}}{n-1}}
$$


The value of $\mathrm{m}$ for liquid solid fluidized bed with as internals in the present study has been observed to be 1.4. The particle terminal velocity and drag co-efficient can be estimated using the following equations (Wen \& Yu, 1966, pp. 610):

Terminal velocity

$$
\begin{aligned}
U_{t} & =\frac{g\left(\rho_{S}-\rho_{g}\right) d_{p}^{2}}{18 \mu_{g}} \\
U_{t} & =\left[\frac{4}{225} \frac{\left(\rho_{S}-\rho_{g}\right)^{2} g^{2}}{\rho_{g} \mu_{g}}\right]^{1 / 3} d_{p} \\
U_{t} & =\left[\frac{3.1\left(\rho_{S}-\rho_{g}\right) g d_{p}}{\rho_{g}}\right]^{1 / 2}
\end{aligned}
$$$$
\text { for } \operatorname{Re}<0.4
$$$$
\text { for } 0.4<\operatorname{Re}<500
$$

for $500<\mathrm{Re}$

and

$C_{D} \operatorname{Re}^{2}=\frac{4 g d_{p}{ }^{3} \rho_{g}\left(\rho_{s}-\rho_{g}\right)}{3 \mu_{g}{ }^{2}}$

The slip velocity estimated using the above analysis has been compared with the experimental observations [Figure 7]. It can be ascertained from the figure 7 that the predicted slip velocity using the present slip velocity model math satisfactorily with the experimental observations.

\section{Conclusion}

Experiments were carried out on bed expansion in a liquid solid fluidized bed with internals. It has been observed from the present investigation that the bed voidage increases with an increase in the internals pitch/twist ration and decreases with an increase in diameter of the string. The bed voidage is higher in fluidized bed with internals than the conventional fluidized bed under same operating conditions. A slip velocity model has been proposed is developed and compared with the experimental data due to the present study.

\section{References}

A. Olivares, M.P. Aznar, M.A. Caballero, J. Gil, E. Frances \& J. Corella. (1997). Biomass gasification: produced gas upgrading by in-bed use of dolo-mite, Ind. Eng. Chem. Res. 36, 5220-5226.

Barnea, E., Mizrahi., J. (1973). Generalised approved to the dynamics of particulate system: Part 1: General correlation for fluidization and sedimentation in solid multi-particle system. Chem. Engg. J1., 5, 171.

Handley, D., Doraisamy, A., Butcher, K. L. \& Franklin, N. L. (1966). A study of the fluid and particle mechanics in liquid-fluidised beds. Trans. Instn Chem. Engrs 44, 260-273.

I Narvaez, A. Orio, M.P. Aznar \& J. Corella. (1996). Biomass gasification with air in an atmospheric bubbling fluidized bed. Effect of six operational variables on the quality of the produced raw gas, Ind. Eng. Chem. Res. 35, $2110-2120$.

I. Narvaez, A. Orio, M.P. Aznar \& J. Corella. (1996). Biomass gasification with air in an atmospheric bubbling fluidized bed. Effect of six operational variables on the quality of the produced raw gas, Ind. Eng. Chem. Res. 35 . 2110-2120.

J. Yang \& A. Renken. (1998). Intensification of mass transfer in liquid fluidized beds with inert particles, Chem. Eng. Process. 37, 537-544.

J.F. Richardson \& M.A. Jeronimo. (1979). Velocity-voidage relations for sedimentation and fluidisation, Chem. Eng. Sci. 34 1419-1422.

Kmiec. (1982). Equilibrium of forces in a fluidized bed-experimental verification, J. Chem. Eng. 23, $133-136$.

Renzo Di Felice. (1995). Hydrodynamics of liquid fluidization. Chem. Eng. Sci., 50, 1220-1225.

Richardson, J. F. \& Zaki, W. N. (1954). Sedimentation and fluidisation. Part I. Trans. Instn Chem. Engrs 32, $35-53$.

Wen, C.Y. \& Yu, Y.H. (1962). Mechanics of fluidization. AIChE Symp. Ser. 62, 100.

Wen, C.Y., Yu, Y-H, (1966). A generalized method for predicting the minimum fluidization velocity. AIChEJ, 12,610 
Table 1. Nomenclature

\begin{tabular}{|l|l|}
\hline$A$ & Cross sectional Area of the column, $\mathrm{m}^{2}$ \\
\hline $\mathrm{C}_{\mathrm{D}}$ & Drag Coefficient \\
\hline $\mathrm{ID}$ & Internal Diameter, $\mathrm{m}$ \\
\hline $\mathrm{d}_{\mathrm{p}}$ & Particle diameter, $\mathrm{m}$ \\
\hline $\mathrm{D}$ & Column diameter, $\mathrm{m}$ \\
\hline $\mathrm{G}$ & Acceleration due to gravity, $\mathrm{m} / \mathrm{s}^{2}$ \\
\hline $\mathrm{L}$ & Bed height, $\mathrm{m}$ \\
\hline $\mathrm{PT}$ & Pitch \\
\hline $\mathrm{TR}$ & Twist ratio \\
\hline $\mathrm{U}_{\mathrm{c}}$ & Velocity of continuous $\mathrm{phase}, \mathrm{m} / \mathrm{s}$ \\
\hline $\mathrm{U}_{\mathrm{d}}$ & Velocity of dispersed $\mathrm{phase}, \mathrm{m} / \mathrm{s}$ \\
\hline $\mathrm{U}_{\mathrm{t}}$ & Terminal settling velocity, $\mathrm{m} / \mathrm{s}$ \\
\hline $\mathrm{U}_{\mathrm{s}}$ & Slip Velocity, $\mathrm{m} / \mathrm{s}$ \\
\hline $\mathrm{U}$ & Superficial liquid velocity, $\mathrm{m} / \mathrm{s}$ \\
\hline $\mathrm{W}$ & Weight of solids in the bed, $\mathrm{kg}$ \\
\hline$\Delta \mathrm{P}$ & Pressure drop, $\mathrm{kg} / \mathrm{m}^{2}$ \\
\hline$\rho_{\mathrm{l}}$ & Density of the liquid, $\mathrm{kg} / \mathrm{m}^{3}$ \\
\hline$\Delta \rho$ & Density difference, $\mathrm{kg} / \mathrm{m}^{3}$ \\
\hline$\rho_{\mathrm{s}}$ & Density of solid, $\mathrm{kg} / \mathrm{m}^{3}$ \\
\hline$\mu$ & Viscosity of liquid, $\mathrm{kg} / \mathrm{m} \mathrm{s}$ \\
\hline$\varepsilon$ & \\
\hline
\end{tabular}




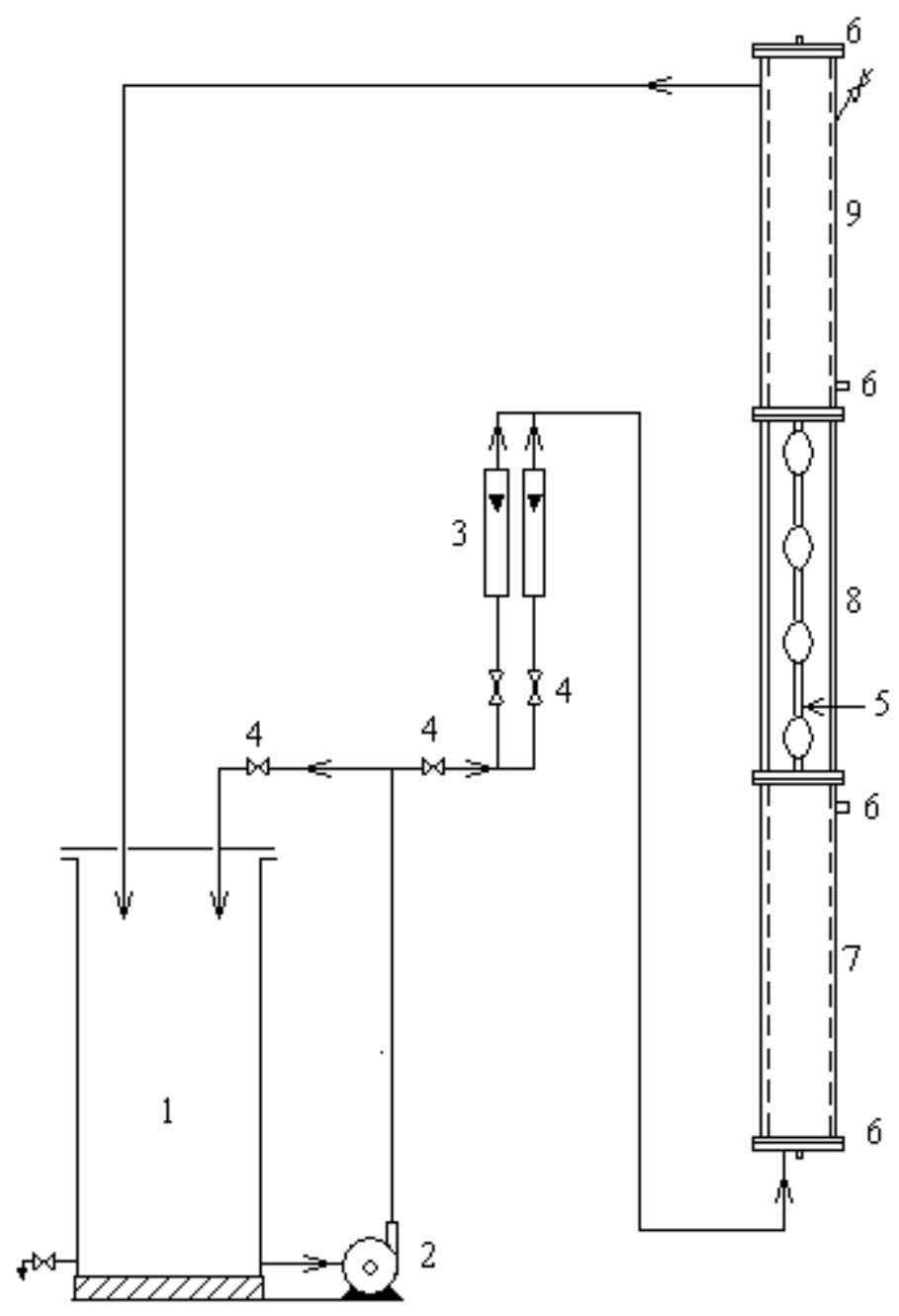

Figure 1. Schematic diagram of the experimental set up

Note. 1: Storage tank; 2: Centrifugal pump; 3: Flow meter; 4: Control valves; 5: Internals; 6: pressure tapings; 7 : Calming section; 8: Test Section, 9: Disengaging section

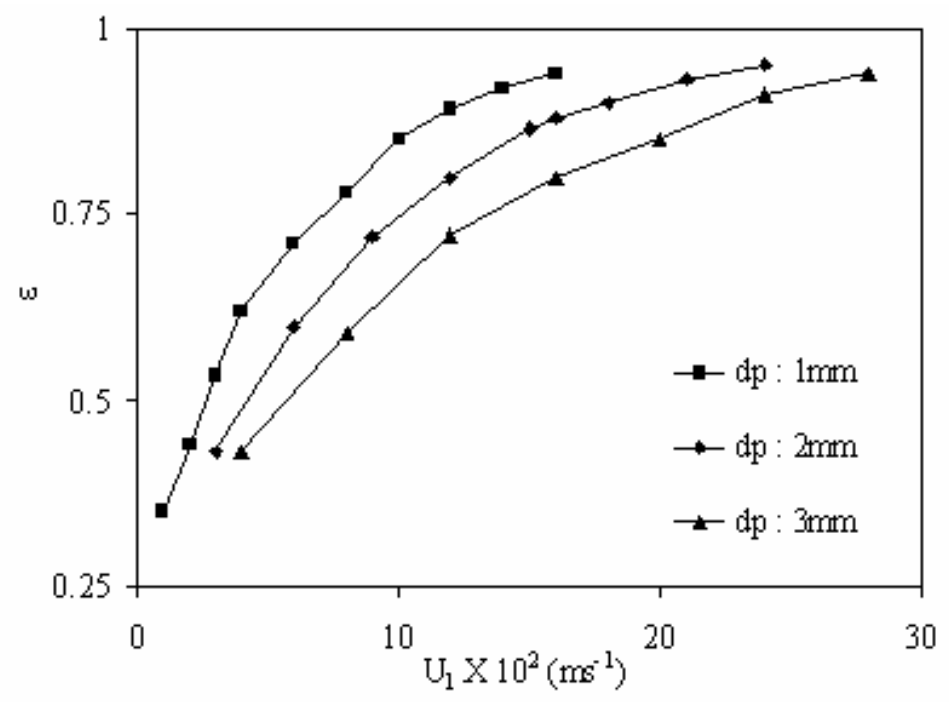

(a) 


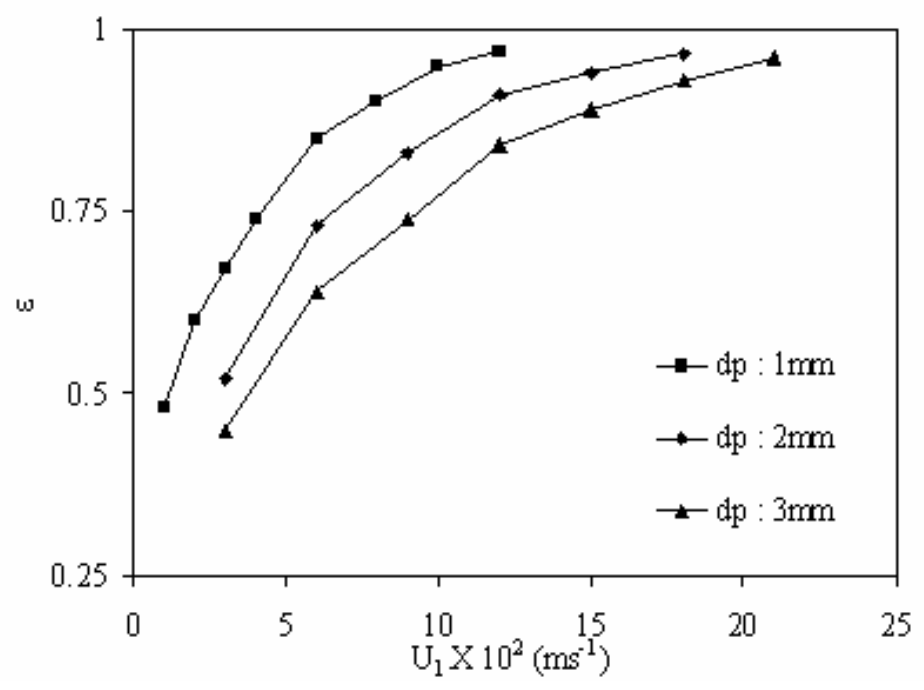

(b)

Figure 2. Variation of bed voidage with liquid flow rate.

Material: Sand; Internal: Sphere; Pitch: (a): 1D; (b): 2D

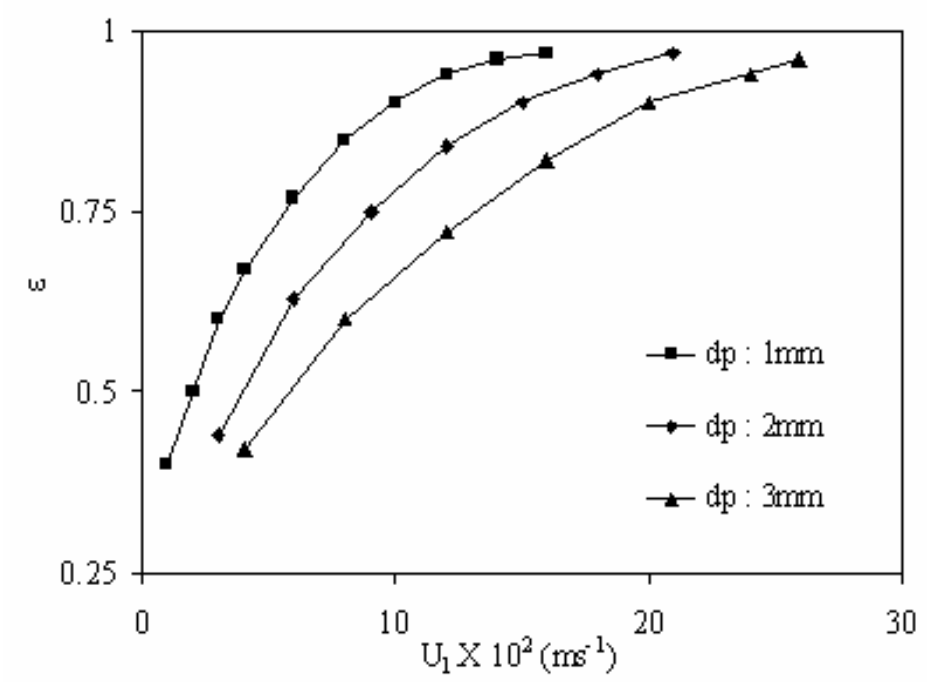

Figure 3. Variation of bed voidage with liquid flow rate.

Material: Glass beads; Internal: Twisted tapes; TR: 3.22 


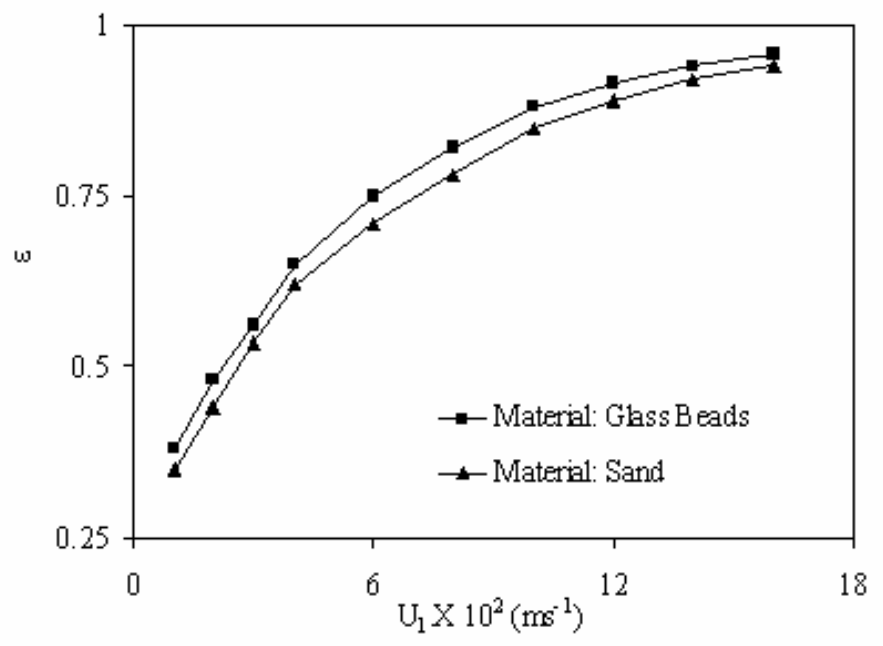

Figure 4. Effect of particle Density on bed voidage: Internal: Sphere: PT: 1D

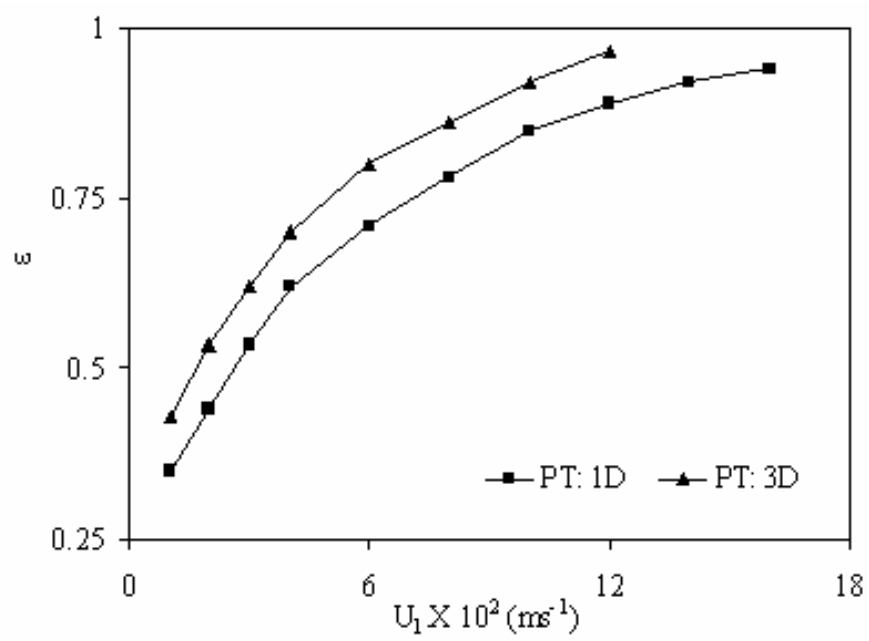

Figure 5. Effect of pitch diameter on the bed voidage. Internal: Sphere; Material: Sand

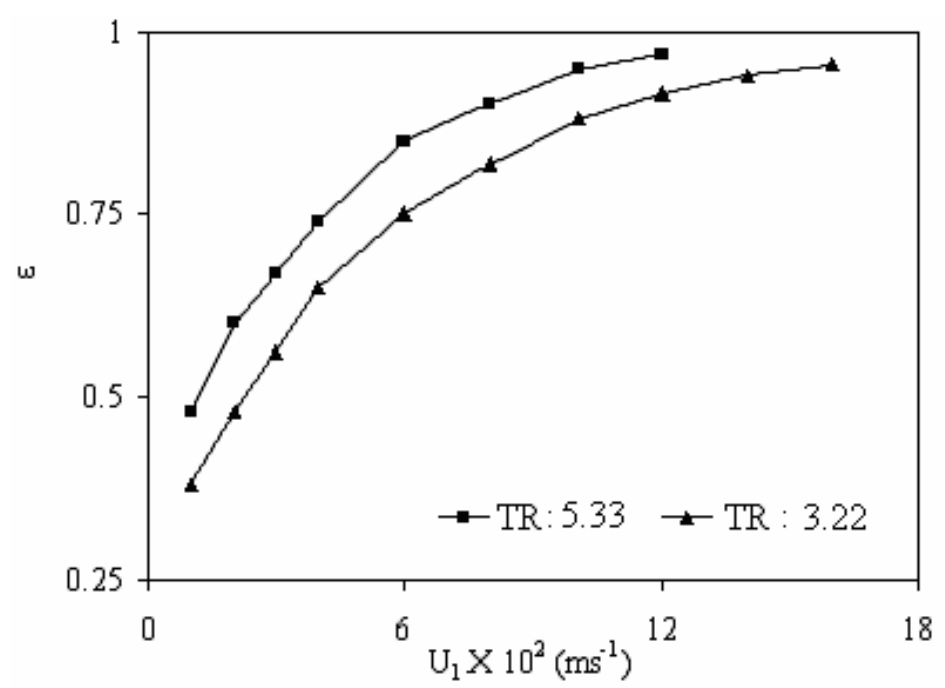

Figure 6. Effect of internal twist ratio on bed voidage. Internal: Twisted tapes; Material: Glass beads 


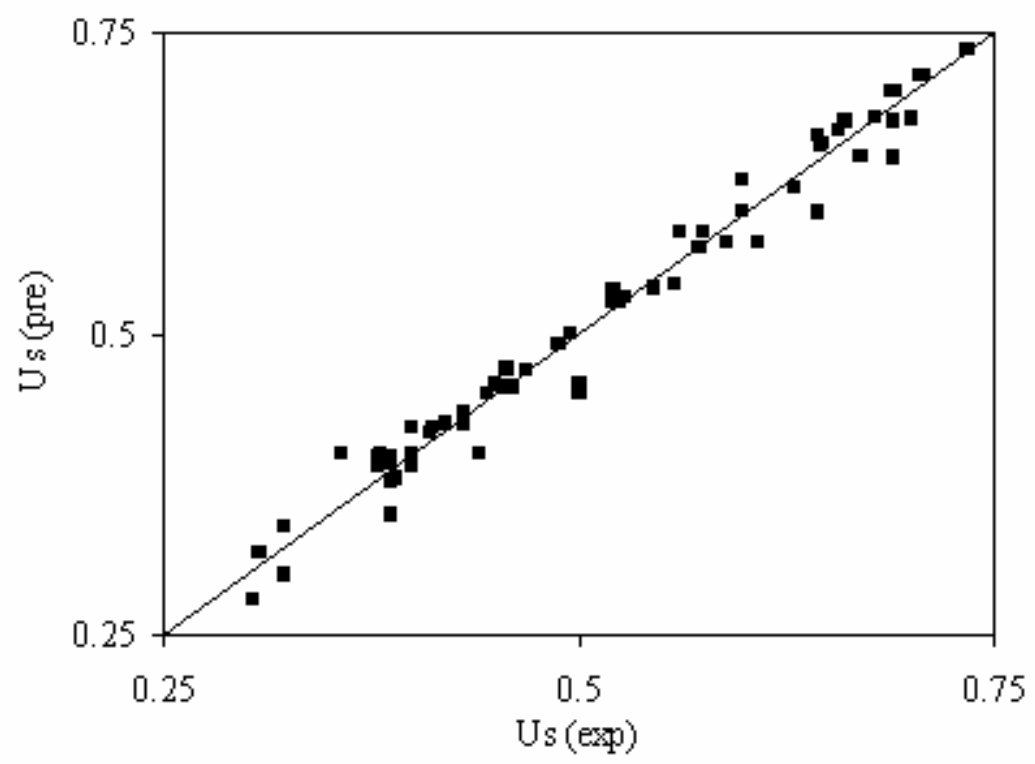

(a)

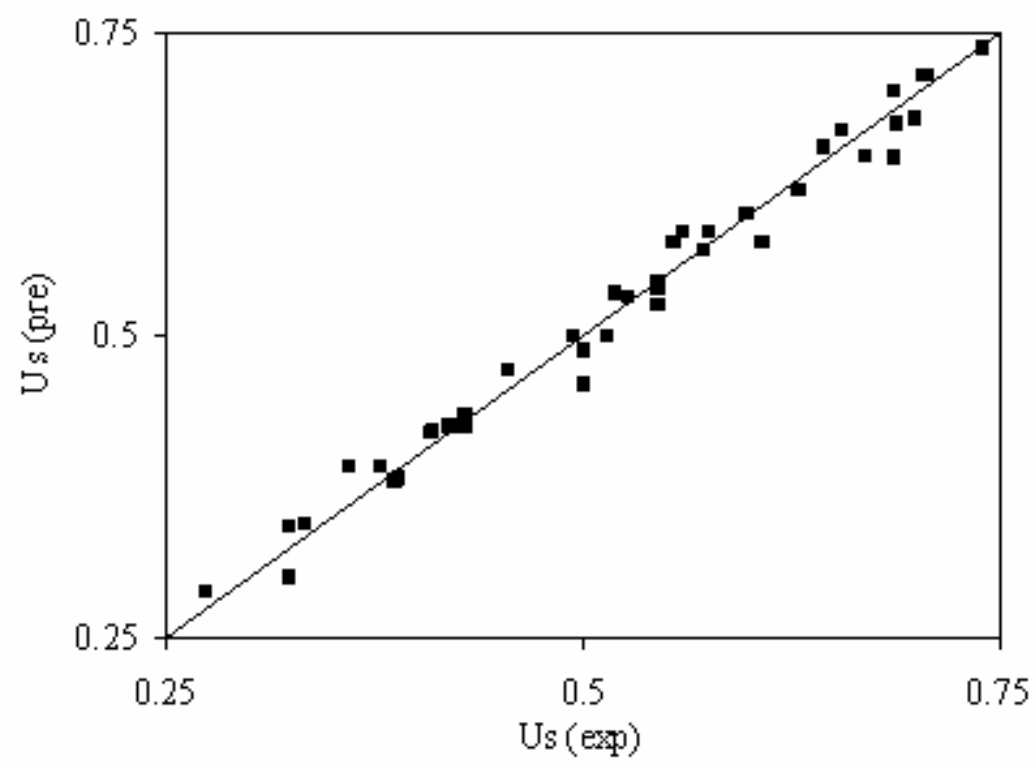

(b)

Figure 7. Comparison of calculated slip velocity with experimental observation

(a) Conventional Liquid-Solid fluidized bed, (b) Liquid-Solid Fluidized bed with internals. 